\title{
Nitric oxide and phosphodiesterase-5 inhibitors: possible treatments for COVID-19 in diabetes
}

\author{
MARTIN B WHYTE, ${ }^{1}$ PRASH VAS, ${ }^{2}$ PHILIP A KELLY, ${ }^{3}$ CHRISTIAN HEISS, ${ }^{4}$ MICHAEL D FEHER ${ }^{5}$
}

Key words: type 2 diabetes, pulmonary microcirculation, COVID-19, nitric oxide, phosphodiesterase-5 inhibitor

Individuals with type 2 diabetes, hypertension and obesity have poor outcomes from coronavirus-19 (COVID-19). The presence of microvascular disease (retinopathy, microalbuminuria or neuropathy) is an independent risk factor for early death in COVID-19. Microvascular dysfunction is a systemic condition which includes pulmonary manifestations. Impaired gas transfer, due to microangiopathy in type 2 diabetes, suggests that individuals will be vulnerable to the pro-inflammatory state and microthrombi characteristic of 'endothelitis' in COVID-19. Drugs that improve blood flow in the intrapulmonary peri-alveolar microcirculation - namely, nitric oxide or phosphodiesterase-5 inhibitors - are therefore promising candidates for clinical trials in COVID-19.

A concerning feature of the coronavirus disease-19 (COVID19) pandemic has been the adverse outcomes observed in individuals with diabetes, obesity and hypertension. ${ }^{1-3}$ People with diabetes are more likely to experience severe outcomes of hospitalisation (odds ratio 2.67, 95\% Cl 1.91 to 3.74), ${ }^{1}$ with mortality rates near $10 \% .{ }^{3}$ A publication comprising 7,336 patients showed the risk of fatal outcome from COVID-19 was up to $50 \%$ higher in patients with diabetes. ${ }^{4}$ In unadjusted analyses, higher glycated haemoglobin $\left(\mathrm{HbA}_{1 \mathrm{c}}\right)$ was associated with worse hospital outcomes in type 2 diabetes. ${ }^{4}$ However, in multivariable analyses of a large series from France, ${ }^{5}$ glycaemic control $\left(\mathrm{HbA}_{1 \mathrm{c}}\right)$ was not significant whereas the presence of macro- and/or microvascular disease are independent risk factors for early death in people with diabetes hospitalised for COVID-19. HbA1c rep-

\footnotetext{
Consultant Diabetologist and Clinical Senior Lecturer in Metabolic Medicine, University of Surrey, King's College Hospital NHS Foundation Trust

2 Consultant Diabetologist, King's College Hospital NHS Foundation Trust 3 Consultant Physician, King's College Hospital NHS Foundation Trust

Professor of Cardiovascular Medicine, University of Surrey, UK

Honorary Professor of Diabetes, University of Oxford, Oxford, UK
}

Address for correspondence: Dr Martin B Whyte Consultant Diabetologist and Clinical Senior Lecturer, The Leggett Building, University of Surrey, GU2 7WG, UK

E-mail: m.b.whyte@surrey.ac.uk

Br J Diabetes 2020;20:81-83

https://doi.org/10.15277/bjd.2020.257 resents glycaemic exposure over the preceding 3 months whereas microvascular burden is a marker of metabolic dysfunction over an individual's lifetime. ${ }^{6}$ Microvascular dysfunction, in particular, is also attracting attention as a pathogenetic mechanism in COVID-19. Viral entry into pneumocytes leads to immune activation and a pro-inflammatory state in the adjacent endothelial cells of the microcirculation. ${ }^{7}$ Microthrombi contribute further to the impediment of microvascular blood flow through the lung. ${ }^{8}$ COVID-19 has therefore been considered an 'endothelitis'. 7

The classic triad of microvascular complications of diabetes (retinopathy, neuropathy and nephropathy) are manifestations of much wider, systemic microvascular dysfunction which also affect vascular beds located in the brain, heart and lung. ${ }^{6,9}$ Reduced lung volumes in diabetes, determined by forced expiratory volume in 1 second $\left(\mathrm{FEV}_{1}\right)$ and vital capacity, relate to the presence of diabetes microvascular complications and glycaemic exposure, ${ }^{10}$ even after adjustment for smoking and gender. Obesity and hypertension themselves contribute to microangiopathy, with inter-relationships between impaired microvascular function, hypertension and insulin resistance. ${ }^{6}$

The transfer capacity of the lung $\left(\mathrm{TL}_{\mathrm{co}}\right)$ is a measure of the capacity for diffusion of oxygen across the alveolus into the microvasculature. It has been shown that, in non-smokers with type 2 diabetes but no overt cardiopulmonary disease, $\mathrm{TL}_{\mathrm{co}}$ was lower than in agematched healthy controls - even after adjusting for cardiac output. ${ }^{11}$ Importantly, individuals with evidence of microvascular dysfunction (retinopathy, microalbuminuria or neuropathy) had worse $\mathrm{TL}_{\mathrm{co}} \cdot{ }^{11}$ Impairment of alveolar-capillary recruitment was evident regardless of obesity status, and suggested that parenchymal changes could impede opening or distention of alveolar capillaries. There is significant 'redundancy' of the pulmonary circulation, such that nearly $50 \%$ of gas transfer may be lost before measures of blood oxygenation diminish. ${ }^{12}$ Therefore, the lower $\mathrm{TL}_{\mathrm{co}}$ seen in diabetes ${ }^{11,13,14}$ would be unlikely to manifest clinically unless a huge stressor was applied to the system. COVID-19 infection is just such a stressor. Severe COVID19 pneumonia produces diffuse alveolar damage and widespread endothelial dysfunction and microthrombi result in matched and unmatched ventilation/perfusion (V/Q) defects, for which an individual with preceding pulmonary microangiopathy would be ill-prepared. Unlike sepsis syndromes, blood pressure and the macrocirculation appear relatively unaffected by COVID-19. ${ }^{15}$ To summarise: a drug that could improve peri-hilar microvascular recruitment may therefore improve oxygenation. 


\section{Nitric oxide}

Vascular nitric oxide (NO) is critical for normal vasodilatation and endothelial function. Endogenous vascular NO production is lower in males and declines with ageing. ${ }^{16}$ Dietary interventions including nitrate ${ }^{17}$ and polyphenols such as flavanols or anthocyanins ${ }^{18}$ are potent means to enhance NO bioavailability via endothelial NO synthase (eNOS) in healthy people, and even in people with vascular disease and type 2 diabetes. ${ }^{19}$ The effect of NO is mediated by the intracellular second messenger cyclic guanosine monophosphate (cGMP). The major cGMP-degrading phosphodiesterase (PDE) is PDE5, which is abundantly expressed in normal lung tissue. ${ }^{20}$ In 2004, during the SARS-coronavirus (SARS-CoV) outbreak, an openlabel study of six patients in the ICU suggested that low-dose inhaled NO for three days could shorten the time of ventilatory support (compared with eight controls). ${ }^{21}$ Contemporaneous in vitro studies suggested a direct effect of $\mathrm{NO}$ on the replication cycle of the SARS coronavirus: the NO donor compound S-nitroso-Nacetylpenicillamine increased survival rate in SARS-CoV infected. epithelial cells. ${ }^{22}$ Based on these same principles of action, trials are underway for the use of inhaled NO to prevent deterioration of $\mathrm{mild} /$ moderate COVID ${ }^{23}$ and to treat established severe disease. ${ }^{24}$ Inhaled NO appears preferable to another pulmonary vasodilator, epoprostenol (a prostacyclin analogue), because the latter is nebulised and requires an inline filter that must be changed every four hours. This would increase the number of times the ventilator circuit has to be opened, thereby increasing the risk of viral transmission to staff.

\section{PDE5 inhibition}

PDE5 inhibition results in increased cGMP levels and prolongs its vasodilating effects in the pulmonary vasculature. Acute administration of a single oral dose of sildenafil causes a significant decrease in mean pulmonary artery pressure and pulmonary vascular resistance, with minimal to no effect on mean arterial pressure. ${ }^{20}$ It may also lead to minimal improvement in cardiac output. ${ }^{20}$ Sildenafil and tadalafil have therefore proved to be a valuable treatment for pulmonary arterial hypertension, a condition characterised by endothelial dysfunction, cell proliferation and vascular remodelling of the pulmonary arteries. ${ }^{20}$ Similarly, COVID-19 may lead to diffuse pulmonary intravascular coagulopathy with ventricular stress induced by pulmonary hypertension. ${ }^{25}$

A further attribute of PDE5 inhibition in COVID could be to offset the ramifications of COVID-19 on angiotensin converting ezyme-2 (ACE2) expression. COVID-19 decreases surface expression of ACE2 during infection. Therefore, angiotensin II is less liable to be degraded to angiotensin-(1-7) by ACE2. Angiotensin II, acting through PDE5, causes vasoconstriction. ${ }^{26} \mathrm{~A}$ tablet preparation that improves $\mathrm{NO}$ action in the intrapulmonary vasculature is therefore an attractive option for COVID-19. At the time of publication, one pilot study is evaluating the role of sildenafil in patients with COVID19 (NCT04304313). This trial, and those of inhaled NO, are restricted to hospitalised patients, albeit with a broad range of disease severity. In view of their mechanism of action, speculatively, PDE5 inhibitors would be of most benefit in those with evidence of pulmonary hypertension or right ventricular dysfunction.

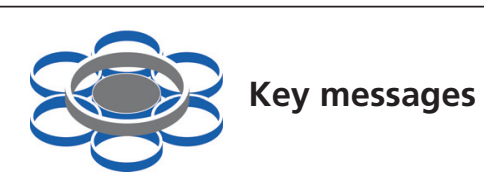

- Impaired gas transfer due to microangiopathy has been reported in type 2 diabetes

- The presence of diabetic microvascular disease is an independent risk factor for early death in COVID-19

- COVID-19 can lead to microthrombi in pulmonary microvasculature

- Drugs that improve blood flow in the intrapulmonary peri-alveolar microcirculation (nitric oxide or phosphodiesterase-5 inhibitors) are being tested in clinical trials in COVID-19

Based on the background information outlined above, we propose that modulation of $\mathrm{NO}$ availability either via direct application, stimulation of eNOS activity or by enhancing downstream signalling by PDE5 inhibition should be considered in treatment trials of COVID-19 infection in diabetes due to their potential to offset the adverse effects of pulmonary microangiopathy.

Author contributions Conceptualisation: MBW, PV. Writing original draft: MBW, PV, PK. Writing, review and editing: $C H, M D F$

\section{Conflict of interest None}

\section{Funding None}

\section{References}

1. Chen Y, Gong X, Wang L, Guo J. Effects of hypertension, diabetes and coronary heart disease on COVID-19 diseases severity: a systematic review and meta-analysis. medRxiv 2020 (Published Online First 30 March 2020). https://doi.org/10.1101/2020.03.25.20043133. 2020

2. NHS England. Type 1 and type 2 diabetes and COVID-19 related mortality in England. Available from: https://www.england.nhs.uk/publication/type-1-and-type-2-diabetes-and-covid-19-related-mortality-in-engl and/ (accessed 28 June 2020).

3. Wu Z, McGoogan JM. Characteristics of and important lessons from the coronavirus disease 2019 (COVID-19) outbreak in China: summary of a report of 72314 cases from the Chinese Center for Disease Control and Prevention. JAMA 2020;323(13):1239-42. https://doi.org/10.1001/jama.2020.2648

4. Zhu L, She Z-G, Cheng X, et al. Association of blood glucose control and outcomes in patients with COVID-19 and pre-existing type 2 diabetes. Cell Metabolism 2020 (Published Online First 1 May 2020). doi: https://doi.org/10.1016/j.cmet.2020.04.021

5. Cariou $B$, Hadjadj S, Wargny $M$, et al, for the CORONADO Investigators. Phenotypic characteristics and prognosis of inpatients with COVID-19 and diabetes: the CORONADO study. Diabetologia 2020;63(8):150015. https://doi.org/10.1007/s00125-020-05180-x

6. Stehouwer CDA. Microvascular dysfunction and hyperglycemia: a vicious cycle with widespread consequences. Diabetes 2018;67(9):172941. https://doi.org/10.2337/dbi17-0044

7. Varga Z, Flammer AJ, Steiger $P$, et al. Endothelial cell infection and endotheliitis in COVID-19. Lancet 2020;395(10234):1417-18. https://doi.org/ 10.1016/S0140-6736(20)30937-5

8. Lax SF, Skok P, Kessler HH, et al. Pulmonary arterial thrombosis in COVID19 with fatal outcome: results from a prospective, single-center, clinicopathologic case series Ann Intern Med 2020 (Published Online First 14 May 2020). https://doi.org/107326/M20-2566

9. Brownrigg JR, Hughes CO, Burleigh D, et al. Microvascular disease and risk of cardiovascular events among individuals with type 2 diabetes: a 
population-level cohort study. Lancet Diabetes Endocrinol 2016; 4(7):588-97. https://doi.org/10.1016/\$2213-8587(16)30057-2

10. Davis WA, Knuiman M, Kendall $P$, et al. Glycemic exposure is associated with reduced pulmonary function in type 2 diabetes: the Fremantle Diabetes Study. Diabetes Care 2004;27(3):752-7. https://doi.org/10.2337/ diacare.27.3.752

11. Chance WW, Rhee C, Yilmaz C, et al. Diminished alveolar microvascular reserves in type 2 diabetes reflect systemic microangiopathy. Diabetes Care 2008;31(8):1596-601. https://doi.org/10.2337/dc07-2323

12. Pellegrino R, Viegi G, Brusasco V, et al. Interpretative strategies for lung function tests. Eur Respir J 2005;26(5):948-68. https://doi.org/10.1183/ 09031936.05 .00035205

13. Mori $\mathrm{H}$, Okubo $\mathrm{M}$, Okamura $\mathrm{M}$, et al. Abnormalities of pulmonary function in patients with non-insulin-dependent diabetes mellitus. Intern Med 1992;31(2):189-93. https://doi.org/10.2169/internalmedicine.31.189

14. Sandler M, Bunn AE, Stewart RI. Cross-section study of pulmonary function in patients with insulin-dependent diabetes mellitus. Am Rev Respir Dis 1987;135(1):223-9. https://doi.org/10.1164/arrd.1987.135.1.223

15. Zhou F, Yu T, Du R, et al. Clinical course and risk factors for mortality of adult inpatients with COVID-19 in Wuhan, China: a retrospective cohort study. Lancet 2020;395(10229):1054-62. https://doi.org/10.1016/S0140$6736(20) 30566-3$

16. Ozdemir B, Yazici A. Could the decrease in the endothelial nitric oxide (NO) production and NO bioavailability be the crucial cause of COVID19 related deaths? Med Hypotheses 2020;144:109970. https://doi.org/ 10.1016/j.mehy.2020.109970

17. Velmurugan S, Gan JM, Rathod KS, et al. Dietary nitrate improves vascular function in patients with hypercholesterolemia: a randomized, double-blind, placebo-controlled study. Am J Clin Nutr 2016;103(1):2538. https://doi.org/10.3945/ajcn.115.116244

18. Heiss C, Keen CL, Kelm M. Flavanols and cardiovascular disease preven- tion. Eur Heart J 2010;31(21):2583-92. https://doi.org.10.1093/eurheartj/ehq332

19. Balzer J, Rassaf T, Heiss $C$, et al. Sustained benefits in vascular function through flavanol-containing cocoa in medicated diabetic patients: a double-masked, randomized, controlled trial. J Am Coll Cardiol 2008; 51(22):2141-9. https://doi.org/ 10.1016/j.jacc.2008.01.059

20. Barnett CF, Machado RF. Sildenafil in the treatment of pulmonary hypertension. Vasc Health Risk Manag 2006;2(4):411-22. https://doi.org/ 10.2147/vhrm.2006.2.4.411

21. Chen L, Liu P, Gao H, et al. Inhalation of nitric oxide in the treatment of severe acute respiratory syndrome: a rescue trial in Beijing. Clin Infect Dis 2004;39(10):1531-5. https://doi.org/10.1086/425357

22. Akerstrom S, Mousavi-Jazi M, Klingstrom J, et al. Nitric oxide inhibits the replication cycle of severe acute respiratory syndrome coronavirus. J Virol 2005;79(3):1966-9. https://doi.org/10.1128/JVI.79.3.19661969.2005

23. ClinicalTrials.gov. Nitric oxide gas inhalation therapy for mild/moderate COVID-19 (NoCovid). NCT04305457. 2020. Available from: https://clinicaltrials.gov/ct2/show/NCT04305457 (accessed 19 May 2020).

24. ClinicalTrials.gov. Nitric oxide gas inhalation in severe acute respiratory syndrome in COVID-19 (NOSARSCOVID). NCT04306393. 2020. Available from: https://clinicaltrials.gov/ct2/show/NCT04306393 (accessed 19 May 2020).

25. McGonagle D, O'Donnell JS, Sharif K, Emery P, Bridgewood C. Immune mechanisms of pulmonary intravascular coagulopathy in COVID-19 pneumonia. Lancet Rheumatol 2020;2(7):437-45. https://doi.org/ 10.1016/S2665-9913(20)30121-1

26. Bornstein SR, Rubino F, Khunti K, et al. Practical recommendations for the management of diabetes in patients with COVID-19. Lancet Diabetes Endocrinol 2020;8(6):546-50. https://doi.org/10.1016/S2213$8587(20) 30152-2$

\section{Obituary - Robert Tattersall}

Just as we go to press the death has been announced of one of the great figures of 20th century clinical diabetes and research, Robert Tattersall. His early work at King's College was on twin studies, before work on Maturity Onset Diabetes of the Young at King's led to a fellowship at the University of Michigan. After returning to the UK he joined a strong group of clinical researchers at Nottingham as a Consultant Physician in Medicine and Diabetes. At Nottingham his many contributions included work on the Somogyi effect, brittle diabetes and dead-in-bed syndrome but perhaps his greatest contribution was in pioneering the role of self-monitoring of glucose. In the 1990's he turned his attention to the history of medicine and after retiring from clinical practice he published many papers and two books Diabetes: The Biography' and The Pissing Evil: A Comprehensive History of Diabetes ${ }^{2}$. Greater details of Robert's life and work can be found in a wonderful tribute written by Simon Heller ${ }^{3}$. Simon's closing paragraph perhaps sums up the great empathy that Robert had with people with diabetes - 'During his career, Robert had recognised that diabetes is an almost-unique disease in that the success of the treatment depends not on the professional carers but on the person with the condition. He encouraged those who worked with him to listen to their patients and ensure that those with the condition were equipped with the complex skills to manage it themselves. Thus, the role of the professional was to support patients in the daunting task of implementing and sustaining these skills on a day-to-day basis. This approach was allied to his ability to identify important questions that could be answered by imaginative clinical studies that changed practice and led directly to improved care.'

\section{References}

1. Tattersall RB. Diabetes: The Biography. Oxford, U.K., Oxford University Press, 2009 (Biographies of Disease series)

2. Tattersall RB. The Pissing Evil: A Comprehensive History Of Diabetes Mellitus. U.K., Swan \& Horn, 2017

3. Simon R. Heller. ' Robert Tattersall, a Diabetes Physician Ahead of His Time' Diabetes Care 2019 Jun;42(6):1005-1008. https://doi.org/10.2337/dci18-0063 